\title{
RECURRENCE OF THYROGLOSSAL DUCT CYST AFTER SISTRUNK OPERATION
}

\author{
Manandhar $S^{1^{*}}$, KandelDR ${ }^{1}$, Panthi $N^{1}$
}

\begin{abstract}
Affiliation
1. Department of Otolaryngology and Head and Neck Surgery
\end{abstract}

\section{ARTICLE INFO}

Received : 23 April, 2019
Accepted $： 09$ September, 2019
Published : 31 December, 2019

(c) Authors retain copyright and grant the journal right of first publication with the work simultaneously licensed under Creative Commons Attribution License CC - BY 4.0 that allows others to share the work with an acknowledgment of the work's authorship and initial publication in this journal.

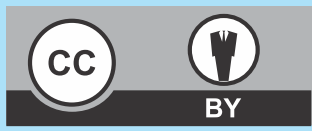

ORA 131

DOI: http://dx.doi.org/10.3126/bjhs.v4i3.27014

\section{* Corresponding Author}

Dr. Sriti Manandhar Associate Professor

Department of Otolaryngology and Head and Neck Surgery B.P. Koirala Institute of Health Sciences, Dharan E-mail: sriticha@gmail.com

ORCID ID:https://orcid.org/0000-0002-1243-2519

\section{Citation}

Manandhar S, Kandel DR, Panthi N. Recurrence of Thyroglossal Duct Cyst after Sistrunk Operation. BJHS 2019;4 (3)10: 786-790.

\section{ABSTRACT}

\section{Introduction}

Thyroglossal duct cyst (TGDC) is the most common form of congenital anomaly in the head and neck region with prevalence of $7 \%$. Embryologically the thyroglossal duct tract gets atrophied by fifth to tenth week of gestation. If it does not atrophied it results in TGDC and operation is the treatment of choice. However, in spite of standard surgical treatment there is recurrence of cyst. Eight percent of thyroglossal duct cyst may reoccur after adequate surgical excision.

\section{Objective}

To identify the recurrence of thyroglossal duct cyst after standard sistrunk's operation.

\section{Methodology}

A retrospective chart review performed in all the patients who were diagnosed with thyroglossal duct cyst and were managed by Sistrunk operation in B.P Koirala Institute of Health sciences, department of Otorhinolaryngology and Head and Neck surgery from 2013 January 1 to 2015 December 31 . The study was conducted on 37 patients' age ranging from 4 years to 68 years. All the patients with the who had undergone Sistrunk's operation and histopathologically diagnosed with thyroglossal duct cyst were analysed through hospital records. All records were reviewed for age, sex, location of cyst in neck and with relation to hyoid bone, postoperative complication and recurrence.

\section{Result}

There was male predominance $67.56 \%$ and female only $32.43 \%$.The most of the patients were between $1-15$ yrs age group (48.64\%). Thirty two patients presented with infrahyoid thyroglossal cyst and five patients with suprahyoid thyroglossal cyst. The post operative complications were in the form of wound dehiscence, haematoma, seroma, infection and there were two cases with recurrence out of thirty seven patients after Sistrunk operation in the form of persistence discharging sinus.

\section{Conclusion}

A Sistrunk's operation is effective in treating primary thyroglossal duct cyst with a comparably low recurrence rate. The intraoperative rupture of cyst is the most important risk factors predicting postoperative recurrence of thyroglossal duct cyst. Meticulous dissection of the thyroglossal duct cyst is very essential for the better surgical outcome.

\section{KEYWORDS}

Recurrence, sistrunk's operation, thyroglossal cyst 


\section{INTRODUCTION}

Thyroglossal Duct Cysts (TGDC) are the most common cervical swelling representing more than $70-75 \%$ of congenital midline neck masses with late presentation in the head and neck region with prevalence of $7 \% .{ }^{1-3}$ In fourth and fifth week of intrauterine life, thyroid analage origin and descends along the from the foramen cecum on the base of the tongue develops caudally along with descend of great vessels.

By the end of seventh week of embryonic life the thyroid gland increases in size becomes a bilobed structure and lies at the root of the neck. The thyroglossal duct usually atrophies and caudal end often remains as a pyramidal lobe. The failure of the tract to disappear leads to epithelial remnant or an open area of duct which may expand into cyst due to accumulation of secretion. They usually present as a painless smooth cystic lump in the anterior neck which moves with deglutition and protrusion of tongue. TGDC may get painful if the cyst gets infected. The studies showed that it can be suprahyoid and infrahyoid and need not be always midline in position. TGDCs are susceptible to recurrent infections, sinus, and fistula and less frequently, carcinomas but less than $1 \%$ of cases. ${ }^{4}$ The post operative complications are divided into major and minor complications. The major complications includes recurrence, nerve paralysis (hypoglossal nerve and lingual nerve), abscess, expanding haematoma which compromises airway with need of tracheostomy, hypothyroidism. Minor complications are infection, wound gap, scar, small haematoma, keloid formation and stitch abscess.

Schlange in 1893 described the treatment of TGDCs by removing the central portion of the hyoid bone along with the cyst, which results in higher recurrence rate. ${ }^{5}$ Wenglowski was the first to observe, from his embryological studies, that resection of the cyst together with the central portion of the hyoid and en bloc resection of the thyroglossal tract up to the foramen caecum would be necessary to prevent recurrence. $^{5}$

In 1920, Walter Ellis Sistrunk proposed the surgical management of this congenital abnormality by doing an en bloc cystectomy, central hyoidectomy, and tract excision up to the foramen caecum, which reduces recurrence rate significantly and this remains the standard surgical approach till today. ${ }^{6,7}$ Sistrunk in his subsequent publication reported that entering the oral cavity was not necessary and that tongue muscle can be resected without opening the mucous membrane of the mouth. ${ }^{8}$ Although Sistrunk's operation is a gold standard surgical management, there are reports of postoperative complication and recurrence from this treatment. ${ }^{9}$ There may be various predisposing factors for the recurrence of thyroglossal duct cyst. ${ }^{10-12}$

Hence we performed a retrospective study to identify the clinical presentation, sex, location of cyst, post operative complication and recurrence rates of TGDCs. These results will be beneficial in predicting outcome and better management of TGDCs.
The objective was to identify the recurrence of thyroglossal duct cysts after Sistrunk's surgery and to identify the predisposing factors of recurrence of thyroglossal duct cysts.

\section{METHODOLOGY}

Aretrospective study done in department of Otorhinolaryngology, Head and Neck Surgery of B.P Koirala Institute of Health Sciences (BPKIHS). Ethical clearance was obtained from the Institutional review committee of BPKIHS. The inclusion criteria were primary diagnosed cases of thyroglossal duct cysts and exclusion criteria were patients who had undergone previous surgical intervention for thyroglossal duct cyst. All the patients who were included in the study had underwent ultrasonography (USG) of neck. USG neck helps to know the postion and nature of the cyst. Those patients who had features of thyroglossal cyst in fine needle aspiration cytology were taken for Sistrunk operation in B.P Koirala Institute Health Sciences in department of ORL and Head and Neck Surgery. After the surgery the confirmation was made with histopathological report. All the 37 patients diagnosed with thyroglossal duct cyst in the period between 2013 January 1 to 2015 December 31 were included.

Sistrunk operation was the procedure of choice in all the patients. In Sistrunk operation is the procedure which involves excision of the cyst, the thyroglossal tract along with the body of the hyoid and core of tongue muscle up to foramen caecum. All the patients were operated by senior consultants of department Otorhinolaryngology, Head and Neck Surgery, BPKIHS. All records were analysed for age, sex, location of cyst in neck and with relation to hyoid bone, postoperative complication and recurrence on the basis of medical records, operative notes, USG and histopathological records. In our patients all of them had done ultrasonography of neck and all had undergone fine needle aspiration cytology but none had undergone computed tomography and magnetic resonance imaging. Any cases which develop cystic swelling or discharging sinus after Sistrunk operation are considered as recurrence.

\section{RESULTS}

Overall there was slightly male predominance with male to female ratio of 2.08:1.

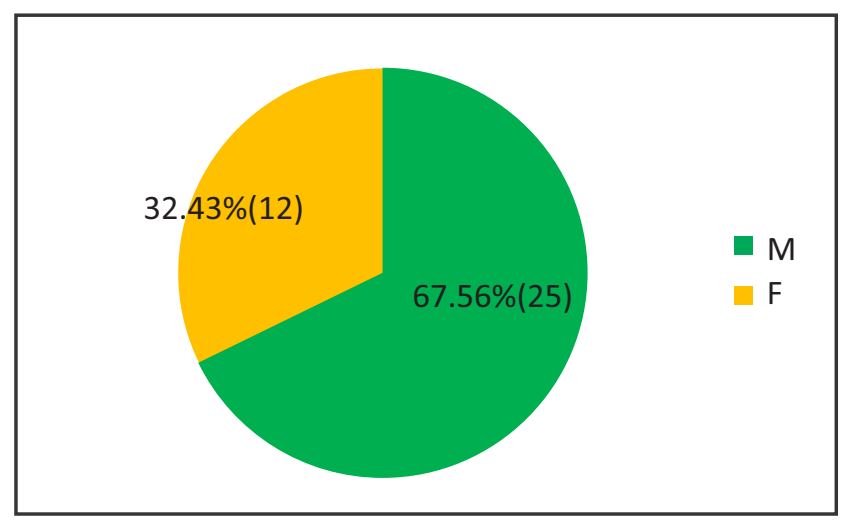


Table1: Showing age distribution:

\begin{tabular}{|c|c|c|}
\hline age & No & $\%$ \\
\hline $\mathbf{1 5}$ & 18 & 48.64 \\
\hline $\mathbf{1 6 - 3 5}$ & 12 & 32.43 \\
\hline $\mathbf{3 5}$ & 7 & 18.91 \\
\hline
\end{tabular}

The above table 1 shows that 15 or less than 15 years group is the commonest. The minimum age of presentation is $4 \mathrm{yrs}$ and the maximum age of presentation is 68yrs. The mean age is $20.54 \mathrm{yrs}$.

Table 2: showing clinical presentation of thyroglossal duct cyst according to the position in neck.

\begin{tabular}{|c|c|c|}
\hline Suprahyoid & Infrahyoid & Total \\
\hline $5(13.51 \%)$ & $32(86.48 \%)$ & 37 \\
\hline
\end{tabular}

In our study we found that $86.48 \%$ of patients presented with infrahyoid cyst.

In the present study all thirty-five patients presented with midline swelling with only two with left side.

Table: 3 Showing post operative complications

\begin{tabular}{|l|c|}
\hline Complication & no \\
\hline Seroma & 5 \\
\hline Wound gap & 4 \\
\hline Infection & 2 \\
\hline Haematoma & 1 \\
\hline Recurrence & 2 \\
\hline Nerve palsy & 0 \\
\hline
\end{tabular}

According to our observation 12 patients have minor complications and two patients had major complications in the form of recurrence but none had nerve palsy.

The patients with minor complications, seroma, wound gap, infection and haematoma were managed conservatively and those with recurrence underwent surgical management.

In all the 36 patients cysts were excised in toto but in only one patient there was a rupture of cyst intraoperatively. The same patient with intraoperative rupture of cyst had recurrence and another with postoperative infection developed recurrence as discharging sinus.

In this study all 37 patients had undergone Sistrunk operation and in this procedure we found recurrence only in two patients which is $5.4 \%$.

\section{DISCUSSION}

Although thyroglossal duct cysts are congenital they can be presented at any age. In our study we found that the age of presentation varied from $4 y$ rs to 68 yrs. Meta-analysis by Allard showed higher incidence of TGDC in children as compare to series by Brousseau et al. in which adults have more malformation. ${ }^{13,14}$ In our study $<15$ years group was higher. The study conducted by Sushail Amin Patigaroo, et al found that most of the patients were from the pediatric age group (73.3\%) were less than 15 years old which is comparable to our study. The mean age of presentation was 10 years and $20 \%$ of the patients were in the age group of 16-30 years of age. ${ }^{15}$ Thirty-five patients presented as midline swelling while only 2 in the lateral left side which is comparable with Shin Tsang study. ${ }^{16}$ Usually the thyroglossal duct lies over the midline of the neck but around 10\% - 24\% of the cysts are located laterally, usually on the left. ${ }^{17}$

In this study $86.48 \%$ of patients were presented as infrahyoid swelling where as $13.51 \%$ of patients were presented as suprahyoid swelling and there was male predominance which was comparable with Shakeel Uz Zaman et al. ${ }^{18}$ A metanalysis studied by Allard found that $2 \%$ of TGDC were intralingual, $24 \%$ suprahyoid, $60 \%$ between the hyoid and thyroid cartilage and $13 \%$ suprasternal. ${ }^{13}$

Studies from different authors found the site of cyst to be variable. TGDCs occur in many different variants: infrahyoid, suprahyoid, juxtahyoid, intralingual, suprasternal and intralaryngeal cysts (extremely rare) ${ }^{19}$. There are also a few cases of intrathyroidal ${ }^{20,21}$ and intrahyoidal TGDCs. ${ }^{22-24}$ The site of the cyst was infrahyoid (80\%), suprahyoid (8\%) and in the supasternal region of the neck $(5 \%)$ and $(2 \%)$ was situated at the base of tongue. ${ }^{15}$ Simple cystectomy is associated with a higher recurrence rate, related to the fact that persistent thyroglossal duct remnants were left in situ at the level of the hyoid bone and beyond. ${ }^{25}$

Though the sistrunk's operation is believed to be the standard surgical procedure for the management of TGDCs different studies shows recurrence rate which varies from $0-15 \%$. Our study showed recurrence in two patients after Sistrunk's operation in which one patient had intraoperative rupture of cyst while manipulating for excision and the same patient had postoperative infection and the patient presented with discharging sinus after fourth week of Sistrunk's surgery with $p$ value $=0.004$. Culture and sensitivity was sent. Culture and sensitivity was sterile. Initially the patient was given oral antibiotic but the discharging sinus did not cure. Then patient underwent for revision surgery where all the fibrotic and adhesive tissue was excised all around and there was no recurrence till now. So care should be taken to prevent intraoperative rupture of cyst as this may lead to incomplete removal of cyst. In another patient with recurrence also had post operative infection with wound gap. Secondary suturing was done and was discharged from the ward but again presented in the outpatient department with discharging sinus on fifth week of surgery. The patient was managed with exploration of neck with excision of the sinus and excision of fibrotic and adhesive tissue all around. In both cases were managed under local anesthesia. According to our study intraoperative rupture of the cyst found to be the major predisposing factor. But it is interesting to note that the patient without intraoperative rupture of cyst also had recurrence. For this case we can predict that some tissue might have been left behind leading to recurrence. So it is very important that surgeon should be very meticulous during the dissection of the tissue for the complete removal to avoid recurrence. However, literature proves that recurrence rate after 
Sistrunk operation can vary from 3.8 to $47 \%$. There are various predisposing factors which leads to recurrence rate seems to be the type of lesion, single versus multiple cyst (dumbbell cyst ), infection, intraoperative rupture of cyst, multiple thyroglossal tract and specific training of the surgeons. $^{26}$

Flageole et al. ${ }^{27}$ and similarly Athow et al. ${ }^{28}$ reported a $40 \%$ recurrence on their initially infected TGDC and an $8 \%$ recurrence on those not infected. Ducic et al. ${ }^{29}$ stated that the only statistically significant difference between successful and unsuccessful outcomes was the presence of infection before surgery.

Von Bismarck and Hollwarth ${ }^{30}$ found that patients with signs of infection or incomplete resection of hyoid bone had a increase risk of developing recurrence and proposed an early operative treatment. However,on the other hand, Burgues Prades et al. ${ }^{31}$ did not find any significant relationship between relapse and a preoperative inflammatory episode of TGDC but only between the use of Sistrunk operation or simple excision. In addition, Ostlie et al. ${ }^{32}$ noted that preoperative infection was not predictive of recurrence, as in their series there was no statistical relationship between the presence of preoperative infection and the development of recurrent disease but only between recurrence and postoperative wound infection. However, they did not investigate the significance between the time of surgery and recurrence of a preoperatively inflammatory TGDC. Yuan-Shin Zhu et al study demonstrated that Sistrunk's operation without routine removal of suprahyoid tissue can provide a comparably low recurrence rate $(0.6 \%)$ in dealing with primary thyroglossal duct cysts. ${ }^{33}$ It had long been proposed that a lack of routine resection of suprahyoid space tissue or the inability to resect adequate amount of suprahyoid tissue may fail to remove the part of thyroglossal duct remnant between hyoid bone and tongue base and result in higher recurrence rates; however, our study demonstrated that proper Sistrunk's operation can provide a comparably low recurrence rate $2 / 37$ that is $5.4 \%$ in dealing with primary thyroglossal dust cysts. ${ }^{34-37}$ In a cohort of 352 thyroglossal duct cyst patients with $21 \%$ non-primary cases. de Tristan et $a l^{38}$ also reported that Sistrunk's operation could achieve a comparably low (4.5\%) overall recurrence rate, supporting the effectiveness of this

\section{REFERENCES}

1. Al-Khateeb TH, Al Zoubi F. Congenital neck masses: a descriptive retrospective study of 252 cases. J Oral Maxillofac Surg. 2007; 65(11):2242-2247. PMID: 17954320.

2 D.S. Foley, M.E. Fallat, Thyroglossal duct and other congenital midline cervical anomalies, Semin. Pediatr. Surg. 2006;15: 70-75. PMID:16616309

3 Mondin, A. Ferlito, E. Muzzi, C.E. Silver, J.J. Fagan, K.O. Devaney, et al. Thyroglossal duct cyst: personal experience and literature review, Auris Nasus Larinx. 2008; 35: 11-25. PMID: 17720342

4 M. Motamed, J.A. McGlashan, Thyroglossal duct carcinoma, Curr. Opin. Otolaryngol. Head Neck Surg. 2004; 12: 106-109. PMID: 15167046

5. Turkyilmaz Z, Sonmez K, Karabulut R. Management of thyroglossal duct cysts in children. Pediatr Int. 2004;46:77-80. PMID: 15043670 technique. According to Suhail Amin Patigaroo, et $\mathrm{al}^{15}$ experience all his cases underwent modified sistrunk procedure in which in addition to sistrunk procedure as the surgical methods of choice and there was no recurrence.

\section{CONCLUSION}

A Sistrunk's operation is effective in treating primary thyroglossal duct cyst with a comparably low recurrence rate. The intraoperative rupture of cyst is the most important risk factors predicting postoperative recurrence of thyroglossal duct cyst. Meticulous dissection of the thyroglossal duct cyst is very essential for the better surgical outcome.

\section{LIMITATIONS OF THE STUDY}

The limitation of this study is short term follow up of four weeks in which patients generally follow up with biopsy report. However, considering that the recurrence of thyroglossal duct cyst is likely to manifest in the first 4 months following surgery ${ }^{39}$ and our institution is the tertiary referral center in this area, it seemed unlikely that a recurrent patient will not return to our institution for further consultation. However, we cannot totally rule out the possibility that recurrent patient(s) may go to another institution, or move to another place, resulting in an underestimation of our recurrence rate. Nonetheless, with basically the same operation technique, de Tristan et al ${ }^{39}$ still demonstrated a comparably low overall recurrence rate $(4.5 \%)$ in their study with sufficient follow-up periods ranging from 7 months to 10 years.

\section{ACKNOWLEDGEMENT}

My sincere thanks to our team of co-authors for there effort in data collection, entry and analysis of the medical records. My regards to medical record section department who helped me in finding records of three years.

\section{CONFLICT OF INTEREST}

No conflict of interest statement.

\section{FINANCIALDISCLOSURE}

None.

6. Athow AC, Fagg NLK, Drake DP. Management of thyroglossal cysts in children. Br J Surg.1989; 76:811-814. PMID: 2765833

7. Bennett KG, Organ $\mathrm{CH}$, Williams $\mathrm{GR}$. Is the treatment for thyroglossal duct cysts too extensive? Am J Surg. 1986; 152:602-605. PMID: 3789282

8. Gisela Wagner and Jesus E. Medina. Excision of thyroglossal duct cyst: The Sistrunk procedure.Operative techniques in otolaryngology 2004.Volume 15,Issue 3, Pages 220-223.DOI: https://doi.org/10.1016/ j. otot.2004.05.001

9. R.K. Chandra, J. Maddalozzo, P. Kovarik. Histological characterization of the thyroglossal tract: implications for surgical management, Laryngoscope. 2001; 111: 1002-1005. PMID: 11404612

10. R. Marianowski, J.L. Ait Amer, M.P. Morisseau-Durand, Y. Manach, S. Rassi. Risk factors for thyroglossal duct remnants after Sistrunk procedure in a pediatric population, Int. J. Pediatr. Otorhinolaryngol. 2003; 67: 19-23. PMID: 12560145 
11. K.M. Ubayasiri, J. Brocklehurst, O. Judd, N. Beasley. A decade of experience of thyroglossal cyst excision, Ann. R. Coll. Surg. Engl. 2013; 95: 263-265. PMID: 23676810

12. K.A. Geller, D. Cohen, J.A. Koempel. Thyroglossal duct cyst and sinuses: a 20-year Los Angeles experience and lessons learned, Int. J. Pediatr. Otorhinolaryngol. 2014;78: 264-267. PMID: 24332664

13. Allard RH. The thyroglossal cyst. Head Neck Surg. 1982; 5:134-146. PMID: 7169333

14. Brousseau VJ, Solares CA, Xu M. Thyroglossal duct cysts: presentation and management in children versus adults. IntJ Pediatr Otorhinolaryngol.2003;67:1285-1290. PMID: 14643470

15. Suhail Amin Patigaroo, Nisar Hussain Dar, Aleena Shafi Jallu, and Rauf Ahmad.Thyroglossal Duct Cysts: A Clinicosurgical Experience. Indian J otolaryngol Head and neck Surg. 2017 Mar; 69(1): 102-107. PMID:28239589

16. Lin ST, Tseng FY, Hsu CJ et al. Thyroglossal duct cyst: a comparison between children and adults. Am J Otolaryngol. 2008; 29:83-87. PMID: 18314017

17. Pollock WF, Stevenson EO. Cysts and sinuses of the thyroglossal duct. Am J Surg. 1966; 112: 225-232. PMID: 5911227

18. Shakeel Uz Zaman, Mubasher Ikram, Mohammad Sohail Awan, Nabeel Humayun Hassan. A Decade of Experience of Management of Thyroglossal Duct Cyst in a Tertiary Care Hospital: Differentiation Between Children and Adults.Indian J Otolaryngol Head Neck Surg. 2017; 69(1):97-101. PMID: 28239588

19. Mondin Y, Ferlito A, Muzzi E, Silver CE, Fagan JJ, Devaney KO, Rinaldo A . Thyroglossal duct cyst: personal experience and literature review. Auris Nasus Larynx. 2008; 35(1):11-25. PMID: 17720342

20. McHenry CR, Danish R, Murphy T, Marty JJ. Atypical thyroglossal duct cyst: a rare cause for a solitary cold thyroid nodule in childhood. Am Surg. 1993; 59(4):223-228. PMID:8489083

21. Johnston R, Wei JL, Maddalozzo J. Intra-thyroid thyroglossal duct cyst as a differential diagnosis of thyroid nodule. Int J Pediatr Otorhinolaryngol. 2003; 67(9):1027-1030. PMID: 12907062

22. North JH, Foley AM, Hamill RL. Intrathyroid cysts of thyroglossal duct origin. Am Surg.1998; 64(9):886-888. PMID: 9731820

23. Tas A, Karasalihoglu AR, Yagiz R, Doganay L, Guven S. Thyroglossal duct cyst in hyoid bone: unusual location. J Laryngol Otol. 2003; 117(8):656-657.PMID: 12956924

24. Bourjat $P$, Cartier J, Woerther JP. Thyroglossal duct cyst in hyoid bone: CT confirmation. J Comput Assist Tomogr. 1988; 12(5):871-873. PMID: 3170849

25. Podoshin L, Fradis M, Goldstein J, Misselevitch I, Boss JH. Intrahyoid thyroglossal cyst. J Laryngol Otol. 1989; 103(5):539-542.PMID: 2754328

26. Noyek AM, Friedberg J. Thyroglossal duct and ectopic thyroid disorders. Otolaryngol Clin North Am. 1981; 14(1): 187.PMID: 7254840

27. Flageole H, Laberge JM, Nguyen LT, Adolph VR, Guttman FM. Reoperation for cysts of the thyroglossal duct. Can J Surg .1995; 38:255-259.PMID: 7788604

28. Athow AC, Fagg NL, Drake DP. Management of thyroglossal cysts in children Br J Surg. 1989; 76:811-814.PMID: 2765833

29. Ducic Y, Chou S, Drkulec J, Ouellette H, Lamothe A Recurrent thyroglossal duct cyst: a clinical and pathologic analysis. Int J Pediatr Otorhinolaryngol. 1998; 44:47-50.PMID: 9720680

30. Von Bismarck S, Hollwarth ME: Thyroglossal duct cysts in paediatric patients: early operative intervention reduces rate of complications. Klin Padiatr. 2001; 213:295-298.PMID:11582530

31. Burgues Prades PL, Gomez Arenas ME, Royo Cuadra Y, Pueyo Gil C, Sainz Samitier A, Esteban Ibarz JA, Alba Losada J:Thyroglossal duct cysts. Do prior inflammatory episodes influence the number of recurrences? An Esp Pediatr 1996; 44:422-424. PMID:8928962

32. Ostlie DJ, Burjonrappa SC, Snyder CL, Watts J, Murphy JP, Gittes GK, Andrews WA, Sharp RJ, Holcomb GW 3rd Thyroglossal duct infections and surgical outcomes. J Pediatr Surg. 2004; 39:396-399.PMID: 15017559

33. Yuan-Shin Zhu, Chung-Ta Lee, Chun-Yen Ou. A 16-year experience in treating thyroglossal duct cysts with a "conservative" Sistrunk approach. Eur Arch Otorhinolaryngol. 2016; 273:1019-1. PMID:25726167

34. Sistrunk WE.The surgical treatment of cysts of the thyroglossal tract. Ann Surg 1920;71:121-122.PMID: 17864229

35. Perkins JA, Inglis AF, Sie KC, Manning SC. Recurrent thyroglossal duct cysts: a 23-year experience and a new method for management. Ann Otol Rhinol Laryngol. 2006; 115(11):850-856.PMID: 17165669

36. Geller KA, Cohen D, Koempel JA.Thyroglossal duct cyst and sinuses: a 20-year Los Angeles experience and lessons learned. Int J Pediatr Otorhinolaryngol. 2014; 78(2):264-26.PMID: 24332664

37. Koempel JA. Thyroglossal duct remnant surgery: A reliable, reproducible approach to the suprahyoid region. Int J Pediatr Otorhinolaryngol. 2014; 78(11):1877-1882.PMID: 25193588

38. de Tristan J, Zenk J, Ku“nzel J, Psychogios G, Iro H. Thyroglossal duct cysts: 20 years' experience (1992-2011). Eur Arch Otorhinolaryngol (Epub ahead of print).2014.PMID: 25135577

39. Bennett KG, Organ CH Jr, Williams GR. Is the treatment for thyroglossal duct cysts too extensive? Am J Surg. 1986; 152(6): 602-605. PMID: 3789282 